\title{
Formulation and Pharmacokinetics of Vitamin E TPGS Melt Dispersion Granules: An Approach to Improve Oral Delivery of Flurbiprofen
}

\author{
Abdul Bari Mohd ${ }^{1}$ and Sateesh Kumar Vemula ${ }^{2,3 *}$
}

${ }^{1}$ Riyadh College of Dentistry and Pharmacy, Riyadh, Kingdom of Saudi Arabia

${ }^{2}$ Department of Pharmaceutics, Chaitanya College of Pharmacy Education and Research, Kishanpura, Hanamkonda, Warangal, Andhra Pradesh, India

${ }^{3}$ Department of Pharmacy, College of Medical and Health Sciences, Wollega University, Nekemte, Ethiopia

\begin{abstract}
Formulation of solid dispersions using BCS class II drugs is one of the fruitful technologies to improve the drug solubility and dissolution rate to improve the bioavailability, but suffers from poor flowability and stability. To overcome the above problems, present research was intended to prepare the solid dispersions using combination of melt dispersion and surface adsorption methods. In the present study flurbiprofen melt dispersion granules were prepared by incorporating vitamin E TPGS as the carrier material and lactose as an adsorbent to improve the dissolution rate and flowability. Melt dispersion granules were evaluated for angle of repose, solubility studies, differential scanning calorimetry, in vitro dissolution studies, stability studies and finally subjected to pharmacokinetic studies. From the differential scanning calorimetry studies, change in the drug peak in formulation revealed the change in drug crystallinity. F4 formulation showed not only good flowability but also complete drug release in 15 min when compared to other formulations and pure drug. From the pharmacokinetic evaluation, F4 formulation showed 1.38fold higher bioavailability and 1.32-fold higher $C_{\max }$ compared to plain flurbiprofen. Hence, the formulated vitamin $E$ TPGS melt dispersion granules were able to improve the dissolution rate as well as the bioavailability of flurbiprofen.
\end{abstract}

Keywords: Bioavailability; Dissolution rate; Melt dispersion; Solid dispersions; Surface adsorption

\section{Introduction}

Oral drug delivery is considered as the most preferable route for chronic treatment of various diseases, due to its greater stability, flexibility in formulation, dosage accuracy, low cost of manufacturing and packaging and patient friendly administration [1]. But most of the drugs belong to poorly water soluble (BCS Class II) category and suffering from poor dissolution and it is worst if given in the form of solid dosage forms like tablets [2]. Hence BCS Class II drugs required to improve the solubility/dissolution to give as oral solid dosage forms. One of the widely used approaches to enhance the solubility and dissolution rate of poorly water soluble drugs is a well-known process of fabricating solid dispersions [3].

Solid dispersions can be defined as the molecular dispersions of drugs in a polymer in solid form and can be prepared by solvent evaporation method and fusion method [4]. In solvent evaporation method, a solvent is employed to dissolve the drug and carrier, and in fusion method, carrier is melted and the drug is dissolved in the melt to obtain the solid dispersions. Once the solid dispersions are obtained they are pulverized to get the desired particle sizes but most of the solid dispersions are suffered from poor flowability and stability that depend on the nature of carrier used. Surface adsorption method is used to absorb the sticky solid dispersion mass on surface of inert carrier to improve the flowability and compressibility. Lactose is one of the widely used inert carrier/diluent, selected as the surface adsorbent due to its inert nature, low cost, good adsorption and compressibility [5]. Hence in the present study combination of melt dispersion and surface adsorption technologies were used to keep the advantages of solid dispersions and to avoid the above disadvantages.

Flurbiprofen (FLB), a poorly water soluble non-steroidal antiinflammatory drug [6] is selected as the model drug in the present study to study the effect of melt dispersion granules on the dissolution rate when compared to plain drug. Some of the recent research examples on dissolution enhancement of FLB are flurbiprofen gelucire solid dispersions [2]; flurbiprofen sublimated fast dissolving tablets [7], flurbiprofen fast disintegrating tablets [8], flurbiprofen fast dissolving tablets [9] and flurbiprofen solid dispersions [10]. In the present study, FLB melt dispersion granules were prepared using vitamin E TPGS as the hydrophilic carrier to enhance the dissolution rate and lactose as an adsorbent to improve the flowability of formulation. Presence of an active ingredient in solid dispersions can decrease in crystal lattice energy and an increase in surface area that provides the improvement in dissolution. The use of surface adsorbents like lactose can convert the molten sticky mass to free flowing and stable granules. Thus the present study is planned to formulate FLB melt dispersion granules to keep the advantages of both solid dispersions and surface adsorption methods as mentioned above.

\section{Materials and Method}

\section{Materials}

Flurbiprofen was gift sample from FDC Limited, Mumbai, India. Vitamin E TPGS was obtained as gift samples from Dr. Reddy's Labs, Hyderabad, India. All other reagents used were of analytical grade and obtained from S.D. Fine Chemicals, Mumbai, India.

\section{Preparation of FLB melts dispersion granules}

FLB solid dispersions using vitamin E TPGS as carrier were

*Corresponding author: Sateesh Kumar Vemula, Associate Professor Department of Pharmacy, College of Medical and Health Sciences, Wollega University, Post Box No: 395, Nekemte, Ethiopia, Tel: 0578619026; E-mail: vemulasatish15@gmail.com

Received January 01, 2016; Accepted January 22, 2016; Published January 29 2016

Citation: Mohd AB, Vemula SK (2016) Formulation and Pharmacokinetics of Vitamin E TPGS Melt Dispersion Granules: An Approach to Improve Oral Delivery of Flurbiprofen. J Bioequiv Availab 8: 089-94. doi:10.4172/jbb.1000274

Copyright: ( 2016 Mohd AB, et al. This is an open-access article distributed under the terms of the Creative Commons Attribution License, which permits unrestricted use, distribution, and reproduction in any medium, provided the original author and source are credited. 
prepared by the fusion method. Accurately weighed amounts of FLB and vitamin E TPGS in various ratios were used to prepare the melt dispersions. The carrier material was melted in a petridish using water bath and the drug was dispersed uniformly in the molten carrier. Then the uniform drug-carrier molten mass was cooled to room temperature. During the cooling process, lactose (adsorbent) was added to molten mass and properly mixed to get the homogenous mixture and passed through the sieve \# 22 to convert into granules. The resulted melt dispersion granules were packed in amber colour bottles and stored in desiccators until use. All the formulations and their compositions were showed in Table 1.

\section{Solubility studies}

From the each prepared formulation an excess amount of FLB melt dispersion granules were transferred into conical flasks which contain $10 \mathrm{ml}$ of media and sonicated for $2 \mathrm{~h}$ at room temperature. Then they were placed on a shaker, agitated at room temperature for 48 $h$ and the suspensions were filtered through Whatman filter paper. The filtrate was suitably diluted and analyzed at $247 \mathrm{~nm}$ wavelengths using double beam UV-Visible spectrophotometer. The same procedure was repeated with different media for all formulations and plain drug.

\section{Determination of drug content}

To estimate the drug content, accurately weighed quantity of prepared melt dispersion granules were transferred to a volumetric flask containing $10 \mathrm{ml}$ of methanol and sonicated for 5 min using bath sonicator. The resulted solution was diluted with suitable media $(7.2$ $\mathrm{pH}$ phosphate buffer), filtered and analyzed for FLB content at $247 \mathrm{~nm}$ using double beam UV-Visible spectrophotometer.

\section{Flow properties-Measurement of angle of repose}

Angle of repose $(\theta)$ is used to determine the frictional force between the granules was measured using fixed funnel method and calculated using the following formula:

$$
\operatorname{Tan} \theta=h / r
$$

In which, $\theta$ is the angle of repose, $\mathrm{h}$ is the height of the cone and $\mathrm{r}$ is radius of the cone base. To measure the angle of repose, a funnel was fixed to a stand so that the lower tip of funnel was $2.5 \mathrm{~cm}$ above the surface. A graph paper was placed on a flat surface. The powder blend was allowed to fall freely on the graph paper through the funnel (6.8 $\mathrm{cm}$ diameter), till the tip ( $8 \mathrm{~mm}$ diameter) of heap formed just touches the funnel. The radius of heap was noted and from this angle of repose was determined.

\section{Differential scanning calorimetry}

The thermograms were recorded for plain drug (FLB), vitamin E TPGS, and F4 formulation using differential scanning calorimeter (Shimadzu, Japan). Accurately weighed amount of $5 \mathrm{mg}$ sample was placed in an open aluminium standard pan was heated at a scanning rate of $50 \mathrm{C} / \mathrm{min}$ from a temperature 0 to $450^{\circ} \mathrm{C}$ under a nitrogen gas flow.

\begin{tabular}{|c|c|c|}
\hline Formulation Code & $\begin{array}{c}\text { FLB: Vitamin E TPGS Ratio } \\
\mathbf{( w / w )}\end{array}$ & $\begin{array}{c}\text { Solid dispersion: Lactose } \\
\text { Ratio }(\mathbf{w} / \mathbf{w})\end{array}$ \\
\hline F1 & $1: 0.1$ & $1: 1$ \\
\hline F2 & $1: 0.2$ & $1: 1$ \\
\hline F3 & $1: 0.3$ & $1: 1$ \\
\hline F4 & $1: 0.4$ & $1: 1$ \\
\hline F5 & $1: 0.5$ & $1: 1.5$ \\
\hline F6 & $1: 0.6$ & $1: 2$ \\
\hline
\end{tabular}

Table 1: Formulation of FLB melt dispersion granules using vitamin E TPGS.

\section{In vitro dissolution study}

USP XXVI Type II dissolution apparatus (Electro lab, TDT-08L) was used to conduct the in vitro dissolution studies at a rotation speed of $50 \mathrm{rpm}$, and temperature of $37 \pm 0.5^{\circ} \mathrm{C}$. The dissolution studies of plain drug, marketed tablet and melt dispersion granules equivalent to $50 \mathrm{mg}$ of FLB were carried out in $900 \mathrm{ml}$ of $7.2 \mathrm{pH}$ phosphate buffer. At standard time intervals $5 \mathrm{ml}$ of sample was collected and replaced with fresh dissolution medium. The samples were filtered through $0.45 \mu \mathrm{m}$ membrane filter (Millipore, USA) and analyzed spectrophotometrically at $247 \mathrm{~nm}$.

\section{Calculation of dissolution parameters}

Dissolution data from above study was further analyzed and compared with plain drug and marketed tablets for percent drug release in $15 \min \left(Q_{15}\right)$, initial dissolution rate (IDR), relative dissolution rate (RDR) [11], dissolution efficiency (DE) and mean dissolution time (MDT) [12].

\section{Stability studies}

The stability of F4 meld dispersion granules was monitored up to 3 months at ambient temperature $\left(30^{\circ} \mathrm{C}\right)$ and relative humidity $(65 \%$ $\mathrm{RH})$ in stability chamber. Samples were removed periodically and evaluated for drug release. The similarity factor $\left(f_{2}\right)$ was calculated between dissolution rates of tablets before and after storage [13]. The similarity factor is a logarithmic reciprocal square root transformation of the sum of squared error and is a measurement of the similarity in the percent (\%) of dissolution between the two curves.

$$
f_{2}=50 \times \log \left\{\left[1+(1 / \mathbf{n}) \sum_{\mathbf{t}=1}{ }^{n}\left(R_{t}-T_{t}\right)^{2}\right]^{-0.5} \times 100\right\}
$$

\section{In vivo bioavailability studies}

Bioavailability studies of FLB melt dispersion granules were approved by the institutional animal ethical committee (Approval No. FMDG/2013/6). In this study, bioavailability of FLB melt dispersion granules (F4 formulation) was compared with FLB plain drug dispersed in sodium carboxy methyl cellulose. Twelve male Wistar rats weighing 200-220 g were used in this study and were fasted overnight but had free access to water. In the present study twelve rats were divided into two equal groups. Group I animals received plain drug (dose $50 \mathrm{mg}$ ) whereas group II rats received melt dispersion granules (dose $50 \mathrm{mg}$ ). Blood samples $(0.5 \mathrm{ml})$ were collected by retro-orbital venous plexus puncture with the aid of glass capillary at $0.125,0.25,0.5,1,1.5,2,3$, $4,6,8,12$ and $24 \mathrm{~h}$ post oral dose. All samples were collected in EDTA coated Eppendorf tubes. Plasma was separated by centrifuging at 3000 rpm for $10 \mathrm{~min}$ and the supernatant plasma was separated and stored at $-40^{\circ} \mathrm{C}$ until the analysis of sample for unchanged drug.

\section{HPLC analysis of FLB in plasma}

FLB concentration in plasma samples was determined using HPLC method adopted from Vemula et al. [14]. The plasma sample was injecting into the HPLC column (loop volume $20 \mu \mathrm{l}$ and flow rate $1 \mathrm{ml} /$ $\mathrm{min}$ ) and the analysis was performed at ambient temperature (8 min run time). The eluents were monitored at $254 \mathrm{~nm}$ using UV detector.

\section{Pharmacokinetic analysis}

Pharmacokinetic parameters were estimated using PK Solver (version 2.0) for each subject by non-compartmental analysis. The peak plasma concentration $\left(\mathrm{C}_{\max }\right)$ and the time to reach peak plasma levels $\left(\mathrm{T}_{\max }\right)$ were directly obtained from the plot of time versus plasma concentration. The area under the curve (AUC) was calculated using 
the trapezoidal rule. The area under first moment curve (AUMC) was obtained from the plot of product of plasma drug concentration and time versus time. The mean residence time (MRT) is calculated from the ratio of AUMC to AUC. The relative bioavailability of FLB melt dispersion granules was calculated against FLB suspension using AUC of both.

\section{Statistical analysis}

The calculated pharmacokinetic parameters were subjected to statistical analysis using analysis of variance (ANOVA) to test the significance of difference. A value of $\mathrm{P}<0.05$ was considered statistically significant.

\section{Results}

\section{Solubility studies of FLB solid dispersions}

Solubility studies of plain FLB and its melt dispersion granules were conducted in different media and the results were shown in Table 2. FLB solubility was highly $\mathrm{pH}$-dependent hence determined in different media, i.e., $0.1 \mathrm{~N} \mathrm{HCl}$, distilled water and phosphate buffer $\mathrm{pH}$ 7.2. It was observed that as the increase in $\mathrm{pH}$ of the media increased the solubility i.e. FLB showed greatest solubility in $7.2 \mathrm{pH}$ phosphate buffer. As the carrier concentration increases, the solubility increased proportionally up to 1:0.4 ratio and after that no significant increase in solubility by increasing the carrier ratio.

\section{Determination of drug content}

Determination of drug content was mainly to check the significant loss of drug during the formulation of solid dispersions/melt dispersion granules. In the present study, all the formulations showed $95-101 \%$ w/w of FLB that indicated the method does not had any significant loss of drug during drug incorporation into carrier.

\section{Differential scanning calorimetry}

DSC thermograms of plain FLB and F4 formulation were showed in Figure 1. DSC studies give information about melting, crystallization, decomposition or change in a heat capacity that explains the physicochemical status of the drug and its interaction with carrier. A sharp endothermic peak corresponding to the melting point of FLB was found at $116^{\circ} \mathrm{C}$ in plain drug but in case of $\mathrm{F} 4$ formulation FLB showed broad peak at $125^{\circ} \mathrm{C}$. This indicates the change in crystalline state of FLB.

\section{Flow properties-measurement of angle of repose}

The results of angle of repose less than $40^{\circ}$ indicates fair to passable flow properties of the powder mixture. Plain FLB showed greater than $40^{\circ}$ angle of repose indicated the poor flow. All the solid dispersions using vitamin E TPGS were formed sticky mass which was difficult to pass through sieve. To overcome this problem lactose was used

\begin{tabular}{|c|c|c|c|}
\hline \multirow{2}{*}{ Formulation Code } & \multicolumn{3}{|c|}{ FLB solubility in $\mathbf{~ g / m l}$} \\
\cline { 2 - 4 } & $\mathbf{0 . 1} \mathbf{~ N ~ H C l}$ & Distilled Water & $\mathbf{7 . 2} \mathbf{~ p H ~ B u f f e r ~}$ \\
\hline Pure FLB & $0.069 \pm 0.15$ & $0.167 \pm 0.11$ & $0.204 \pm 0.16$ \\
\hline F1 & $0.124 \pm 0.16$ & $0.298 \pm 0.12$ & $0.435 \pm 0.29$ \\
\hline F2 & $0.141 \pm 0.12$ & $0.378 \pm 0.25$ & $0.541 \pm 0.18$ \\
\hline F3 & $0.159 \pm 0.18$ & $0.476 \pm 0.22$ & $0.582 \pm 0.11$ \\
\hline F4 & $0.172 \pm 0.32$ & $0.567 \pm 0.18$ & $0.648 \pm 0.27$ \\
\hline F5 & $0.176 \pm 0.21$ & $0.569 \pm 0.11$ & $0.651 \pm 0.14$ \\
\hline F6 & $0.178 \pm 0.12$ & $0.572 \pm 0.28$ & $0.654 \pm 0.21$ \\
\hline
\end{tabular}

Table 2: Solubility of FLB-vitamin E TPGS melt dispersion granules in various solvents $(\mathrm{mg} / \mathrm{ml})$. as surface adsorbent and all formulations showed good flowability and the values were given in Table 3. As the concentration of carrier increases more than 1:0.4 ratio, it requires more than $1 \mathrm{~g}$ lactose to give good flow.

\section{In vitro dissolution study}

Figure 2 was shown the drug release pattern of F1-F6 formulations and Figure 3 represents comparison between F4 melt dispersion granules and plain drug and marketed tablet. From the in vitro dissolution studies, F4 formulation showed fast dissolution (99.02 \pm $1.07 \%$ in $15 \mathrm{~min}$ ) than other formulations and improved significantly when compared to plain drug and marketed tablet.

\section{Calculation of dissolution parameters}

All the calculated dissolution parameters were given in Table 3. Q15 and IDR values of F4 formulation was found to be $99.28 \pm$ $0.96 \%, 6.619 \% / \mathrm{min}$ and significant improvement was observed when compared to plain drug and marketed tablets. The DE of F4 melt dispersion granules was found to be 76.73 and it is increased by 10fold when compared to plain drug and 3.5-fold compared to marketed tablets. MDT values were given in Table 3 and shown low value in case of melt dispersion granules.

\section{Stability studies}

The stability of F4 melt dispersion granules was carried and the

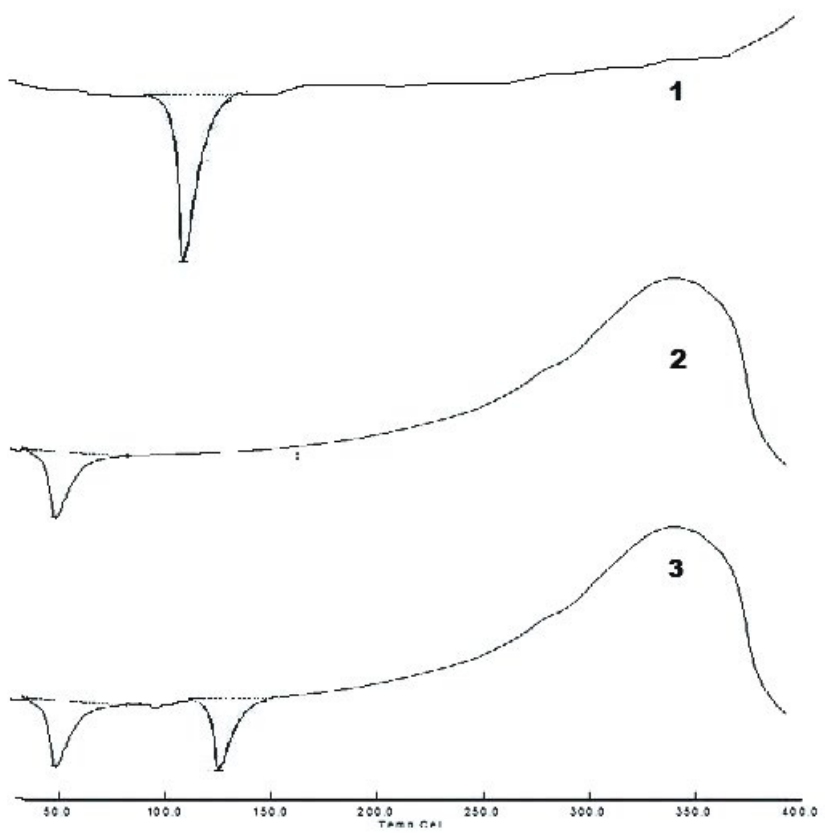

Figure 1: DSC thermograms of 1) FLB 2) Vitamin E TPGS 3) F4 melt dispersion granules.

\begin{tabular}{|c|c|c|c|c|c|}
\hline Formulation & $\mathbf{Q}_{\mathbf{1 5}} \mathbf{( \% )}$ & $\mathbf{D E}_{\mathbf{3 0}}(\mathbf{\%})$ & IDR (\%/min) & MDT (min) & $\begin{array}{c}\text { Angle of } \\
\text { Repose (\%) }\end{array}$ \\
\hline Plain drug & $7.12 \pm 1.32$ & 7.33 & 0.475 & 14.60 & $47.28 \pm 1.42$ \\
\hline $\begin{array}{c}\text { Marketed } \\
\text { tablets }\end{array}$ & $23.64 \pm 1.87$ & 21.54 & 1.576 & 14.46 & - \\
\hline $\begin{array}{c}\text { F4 Melt } \\
\text { dispersion } \\
\text { granules }\end{array}$ & $99.28 \pm 0.96$ & 76.73 & 6.619 & 7.28 & $28.43 \pm 1.27$ \\
\hline
\end{tabular}

Table 3: Determination of dissolution parameters and angle of repose (Mean \pm $\mathrm{SD}, \mathrm{n}=3$ ). 


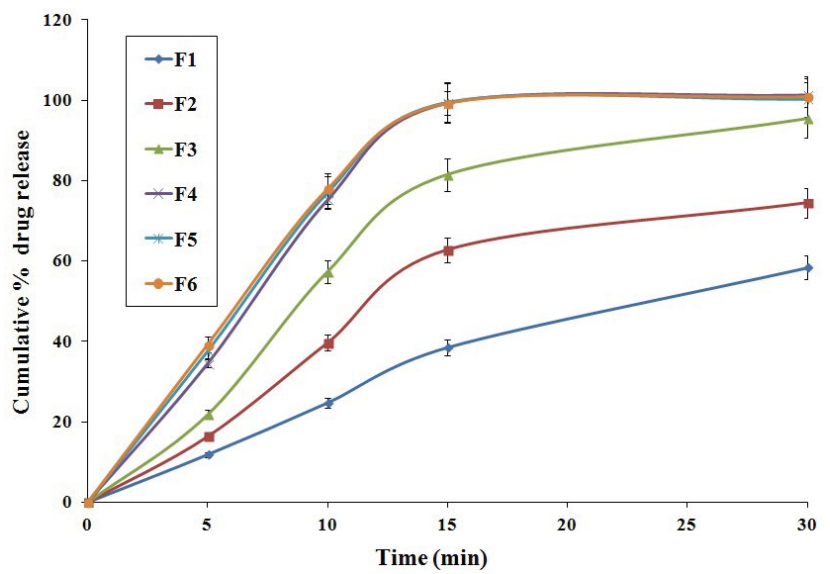

Figure 2: In vitro dissolution studies of F1-F6 melt dispersion granules $(n=3)$.

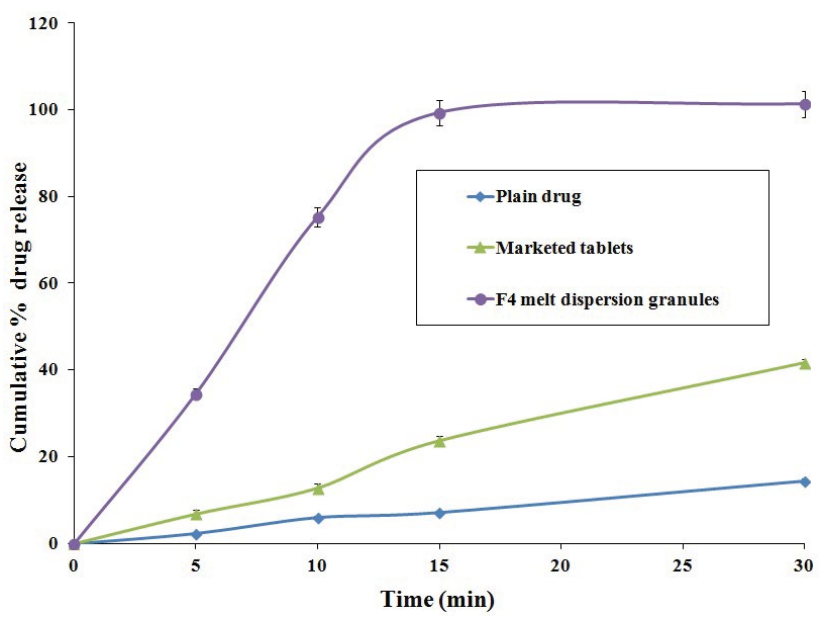

Figure 3: Comparison of FLB release from plain drug, marketed tablets and F4 melt dispersion granules $(n=3)$.

\begin{tabular}{|c|c|c|c|c|}
\hline Time (min) & $\begin{array}{c}\text { Before } \\
\text { storage }\end{array}$ & $\begin{array}{c}\text { After } \mathbf{3} \text { months } \\
\text { storage }\end{array}$ & $\begin{array}{c}\text { t-test at } \mathbf{0 . 0 5} \\
\text { LS }\end{array}$ & $\begin{array}{c}\text { Similarity } \\
\text { Factor }\left(\boldsymbol{f}_{\mathbf{2}}\right)\end{array}$ \\
\hline 0 & $0.00 \pm 0.00$ & $0.00 \pm 0.00$ & Not Significant & 84.58 \\
\hline 5 & $34.56 \pm 1.12$ & $32.12 \pm 1.23$ & & \\
\hline 10 & $75.28 \pm 1.34$ & $73.89 \pm 0.98$ & & \\
\hline 15 & $99.28 \pm 0.96$ & $97.12 \pm 1.07$ & & \\
\hline
\end{tabular}

Table 4: Stability studies of FLB F4 melt dispersion granules $(n=3)$.

samples were tested for dissolution after 3 months of storage. From the statistical analysis there was no significant difference between before and after storage $(\mathrm{P}<0.05)$ and the similarity factor $(\mathrm{f} 2)$ was found as 84.58 between before and after storage of 3 months Table 4 .

\section{Pharmacokinetic analysis}

In this experiment, pharmacokinetic evaluation was carried out for both F4 melt dispersion granules and plain drug suspension. The mean FLB plasma concentrations following the oral administration of both were showed in Figure 4 and the mean pharmacokinetic parameters of both were given in Table 5. In the above pharmacokinetic parameters, $\mathrm{T}_{\text {max }}$ represents rate of absorption and AUC is related to extent of absorption while $\mathrm{C}_{\max }$ is related to both.

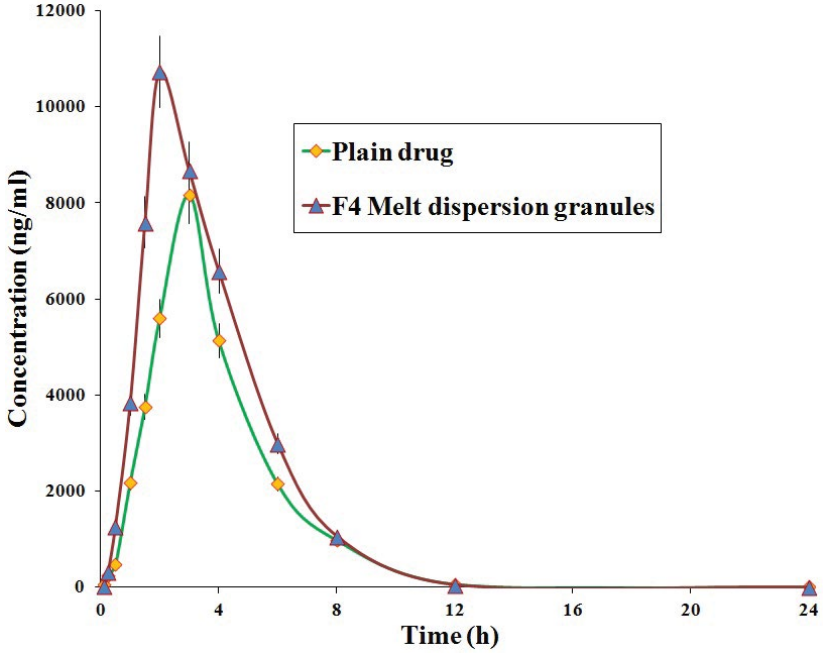

Figure 4: In vivo plasma concentrations of FLB plain drug and F4 melt dispersion granules $(n=6)$.

\begin{tabular}{|c|c|c|c|}
\hline Parameters & Plain drug & $\begin{array}{c}\text { F4 melt dispersion } \\
\text { granules }\end{array}$ & $\begin{array}{c}\text { t-test at } \mathbf{0 . 0 5} \\
\text { LS }\end{array}$ \\
\hline $\mathrm{T}_{\max }(\mathrm{h})$ & $3.00 \pm 0.01$ & $2.00 \pm 0.01$ & Significant \\
\hline $\mathrm{C}_{\max }(\mathrm{ng} / \mathrm{ml})$ & $8156.34 \pm 587.42$ & $10736.78 \pm 182.67$ & Significant \\
\hline $\mathrm{AUC}_{0 \text {-inf }}\left(\mathrm{ng} / \mathrm{ml} l^{*} \mathrm{~h}\right)$ & $\begin{array}{c}30956.26 \pm \\
638.68\end{array}$ & $42764.23 \pm 615.39$ & Significant \\
\hline $\mathrm{AUMC}_{\text {0-inf }}\left(\mathrm{ng} / \mathrm{ml}^{*} \mathrm{~h}^{2}\right)$ & $\begin{array}{c}120578.46 \pm \\
2978.82\end{array}$ & $152352.28 \pm 3245.47$ & Significant \\
\hline MRT $(\mathrm{h})$ & $3.89 \pm 0.021$ & $3.56 \pm 0.028$ & $\begin{array}{c}\text { Not } \\
\text { Significant }\end{array}$ \\
\hline Relative bioavailability & 1.38 & & \\
\hline
\end{tabular}

Table 5: Pharmacokinetic parameters of FLB plain drug and F4 melt dispersion granules (Mean \pm SD $n=6$ )

\section{Discussion}

With the aim to improve the solubility and dissolution rate of water insoluble FLB, the present study was planned to prepare solid dispersions using fusion method. The resulted powder form the combination of fusion method and surface adsorption method was converted into granules, hence they were called as melt dispersion granules. The prepared formulations were evaluated for solubility studies, DSC, angle of repose, in vitro dissolution studies, stability studies and in vivo bioavailability studies.

Determination of aqueous solubility of prepared solid dispersion formulations is one of the significant factors, which has the strong influence on the dissolution rate. The solubility of FLB melt dispersion granules was determined in $0.1 \mathrm{~N} \mathrm{HCl}$, distilled water and phosphate buffer $\mathrm{pH} 7.2$ and the results indicated that the solubility was increased as the $\mathrm{pH}$ of the media increased. The aqueous solubility of the FLB is highly $\mathrm{pH}$-dependent in the physiological range due to its $\mathrm{pKa}$ of 4.16. As a weak acid, FLB has a higher solubility in a basic aqueous environment, hence showed highest solubility in $7.2 \mathrm{pH}$ phosphate buffers. Similar type of results observed in FLB solid dispersions using gelucires [2]. Among all the formulations, as increasing the carrier concentration, the FLB solubility was increased at a significant level, but after some level there was no proportional increase in solubility by increasing carrier ratio. Similar kind of results was observed in gliclazide solid dispersions using vitamin E TPGS [15]. 
All the formulations were evaluated for drug content uniformity and they were found to contain $95-101 \% \mathrm{w} / \mathrm{w}$ of FLB, which was within the pharmacopoeial limits (90-110\%). From the preliminary studies to select the adsorbent, lactose was shown good to improve the flowability of solid dispersions when compared to microcrystalline cellulose and dibasic calcium phosphate. Hence in the present study, lactose was selected as the adsorbent to improve the flowability of solid dispersions. From the results of angle of repose F1-F4 formulations required $1 \mathrm{~g}$ of lactose to show the good flow properties but F5 and F6 formulations 1 $\mathrm{g}$ of lactose is inefficient to improve flowability. They required $1.5-2 \mathrm{~g}$ of lactose to show good flowability due to high amount of carrier. Similar kind of results was observed in valsartan melt dispersion granules developed by Chella and Tadikonda [5]. From the DSC studies, a sharp endothermic peak was observed at $116^{\circ} \mathrm{C}$ in plain drug corresponding to the melting point of FLB, but in case of F4 formulation FLB showed broad peak at $125^{\circ} \mathrm{C}$. This indicates the change in crystalline state of FLB and may be converted to amorphous form. This might be one of the reasons to enhance the solubility and dissolution rate of melt dispersed granules.

From the in vitro dissolution studies, the order of dissolution was observed as follows; melt dispersion granules $>$ marketed tablets $>$ plain drug (Figure 3) and this was the clear indication of dissolution enhancement in case of melt dispersion granules. The dissolution rate enhancement might be due to combined effect of improved wettability, conversion of crystalline to amorphous form and reduction in drug particle size during the formation of solid dispersions [16,17]. Overall increase in the dissolution performance of the F4 formulation was described with the help of dissolution parameters $\left(Q_{15}\right.$, IDR, DE, RDR and MDT) and when compared with plain drug and marketed tablets, all the above parameters were increased in case of $\mathrm{F} 4$ formulation. In a study developed by Vemula et al., i.e., formulation of flurbiprofen tablets, similar type of improvement in IDR, DE, RDR was reported [8]. From the stability studies of F4 formulation, in vitro dissolution data showed that there was no significant change before and after storage. The calculated similarity factor was found to be 84.58 , which is more than 50 indicates similarity between the dissolution profile before and after storage.

From the in vivo bioavailability studies, significant difference in the plasma concentration time profile of FLB was observed from F4 melt dispersion granules to plain drug after oral administration was due to the improved aqueous solubility and dissolution rate. $\mathrm{C}_{\max }$ was improved with F4 melt dispersion granules $(10736.78 \pm 182.67 \mathrm{ng} / \mathrm{ml}$ at $2 \mathrm{~h} \mathrm{~T}_{\max }$ ) in comparison to plain drug suspension due to improved solubility and dissolution rate and it indicates the significant increase in bioavailability. The AUC and MRT (illustrate the resident time in GIT) of F4 melt dispersion granules were found as $42764.23 \pm 615.39$ $\mathrm{ng}-\mathrm{h} / \mathrm{ml}$ and $3.56 \mathrm{~h}$ respectively and they were improved in comparison to plain drug. In a reported study by Mettu et al., i.e., flurbiprofen fast dissolving tablets, similar type of results were observed [9]. The relative bioavailability was found to be 1.38 . From the above results, it was confirmed that the F4 melt dispersion granules showed significant improvement in bioavailability of FLB. To conclude, development of melt dispersion granules using vitamin E TPGS and lactose can be a potential alternative method to enhance not only dissolution rate and bioavailability but also flowability and stability of water-insoluble drugs like FLB.

\section{Conclusion}

An effort was made to formulate the flurbiprofen melt dispersion granules by incorporating vitamin E TPGS and lactose using combination of melt dispersion and surface adsorption technologies to enhance the dissolution rate and bioavailability. The improvement in the both dissolution rate and bioavailability was brought with the help of vitamin E TPGS and improved flowability due to lactose addition. The prepared melt dispersion granules were also possesses good stability. The results of the pharmacokinetics proved that the there was a significant improvement of bioavailability in case of F4 formulation when compared to plain drug. Hence it was a prominent approach to enhance the dissolution rate and bioavailability of poorly soluble drugs like flurbiprofen.

\section{Acknowledgement}

The authors acknowledge the FDC Limited, Mumbai, India and Dr. Reddy's Labs, Hyderabad, India for gift samples. The authors also thank to Management Chaitanya College of Pharmacy Education and Research for providing facilities.

\section{Declaration of Interest}

The authors report no conflicts of interest.

\section{References}

1. Vasconcelos T, Sarmento B, Costa P (2007) Solid dispersions as strategy to improve oral bioavailability of poor water soluble drugs. Drug Discov Today 12 : 1068-1075.

2. Daravath B, Tadikonda RR, Vemula SK (2015) Formulation and pharmacokinetics of gelucire solid dispersions of flurbiprofen. Drug Dev Ind Pharm 41: 1254-1262.

3. Emara LH, Badr RM, Elbary AA (2002) Improving the dissolution and bioavailability of nifedipine using solid dispersions and solubilizers. Drug Dev Ind Pharm 28: 795-807.

4. Chauhan B, Shimpi S, Paradkar A (2005) Preparation and evaluation of glibenclamide-polyglycolized glycerides solid dispersions with silicon dioxide by spray drying technique. Eur J Pharm Sci 26: 219-230.

5. Chella N, Tadikonda R (2015) Melt dispersion granules: formulation and evaluation to improve oral delivery of poorly soluble drugs-a case study with valsartan. Drug Dev Ind Pharm 41: 888-897.

6. Vemula SK (2015) A Novel Approach to Flurbiprofen Pulsatile Colonic Release: Formulation and Pharmacokinetics of Double-Compression-Coated MiniTablets. AAPS PharmSciTech 16: 1465-1473.

7. Vemula SK, Reddy SG (2015) Formulation and pharmacokinetics of flurbiprofen sublimated fast dissolving tablets. Open Pharm Sci J 2: 56-65.

8. Vemula SK, Veerareddy PR (2011) Fast disintegrating tablets of flurbiprofen: formulation and characterization. Lat Am J Pharm 30: 1135-1141.

9. Mettu SR, Veerareddy PR (2013) Formulation, evaluation and pharmacokinetics of flurbiprofen fast dissolving tablets. Brit J Pharm Res 3: 617-631.

10. Patel JH, Tiwari P, Patel JS (2011) Solid dispersion based tablets of poorly soluble drug flurbiprofen. Am J Pharmtech Res 1: 18-24.

11. Ahuja N, Katare OP, Singh B (2007) Studies on dissolution enhancement and mathematical modeling of drug release of a poorly water-soluble drug using water-soluble carriers. Eur J Pharm Biopharm 65: 26-38.

12. Vemula SK, Aila S, Bontha VK (2015) Formulation and evaluation of ezetimibe liquisolid tablets: An approach to enhance the dissolution rate. Brit J Pharm Res 7: 440-450.

13. Vemula SK (2015) Formulation and pharmacokinetics of colon-specific doublecompression coated mini-tablets: Chronopharmaceutical delivery of ketorolac tromethamine. Int J Pharmaceut 491: 35-41.

14. Veerareddy PR, Vemula SK (2012) Formulation, evaluation and pharmacokinetics of colon targeted pulsatile system of flurbiprofen. J Drug Target 20: 703-714.

15. Devireddy SR,Veerareddy PR (2012) Solubility and bioavailability improvement of gliclazide by solid dispersions using novel carriers. Int J Drug Del 4: 455-461. 
Citation: Mohd AB, Vemula SK (2016) Formulation and Pharmacokinetics of Vitamin E TPGS Melt Dispersion Granules: An Approach to Improve Oral Delivery of Flurbiprofen. J Bioequiv Availab 8: 089-94. doi:10.4172/jbb.1000274

16. Dordunoo SK, Ford JL, Rubinstein MH (1991) Preformulation studies on solid dispersions containing triamterene or temazepam in polyethylene glycols or gelucire 44/14 for liquid filling of hard gelatin capsules. Drug Dev Ind Pharm 17: $1685-1713$.
17. Bandarkar SF, Ibrahim SK (2011) Lyophilized gliclazidepoloxamer, solid dispersions for enhancement of in vitro dissolution and in vivo bioavailability. Int J Pharm Pharm Sci 3: 122-127. 